\title{
Is your loyalty programme really building loyalty? Why increasing emotional attachment, not just repeat buying, is key to maximising programme success \\ Received (in revised form): 27th November, 2003
}

\section{Garth Hallberg}

is a New York-based strategic marketing consultant, teacher and writer. His book, 'All consumers are not created equal' (John Wiley \& Sons, New York, 1995), introduced the concept of differential marketing, an overarching strategic vision for the integration of direct marketing thinking and tools into the communications plans of traditional media advertisers through a focus on high-value consumers. He was a key contributor to OgilvyOne's analysis of the Brandz ${ }^{\mathrm{TM}}$ database and the creation of the Ogilvy Loyalty Index.

\begin{abstract}
Profitable incremental sales should not be the only criterion for success for loyalty programmes. New findings from a database of more than 600,000 consumer interviews around the world indicate that if marketers are truly committed to building brand loyalty, they must use their programmes to build consumers' emotional attachment to the brand, not just be content with repeat buying. In doing so, they will maximise and better sustain the financial success of their programmes and may even help the brand become a category leader.
\end{abstract}

Garth Hallberg Garth R. Hallberg Inc., 84 East Ridge Road, POB 108, Waccabuc, NY 10597 USA.

Tel: +1914 763 2398; e-mail: ghallberg@ differentialmarketing.com
The mention of a 'loyalty programme' usually conjures up the image of a 'pay-for-play' or 'points' scheme, where consumers are rewarded for their purchases with various incentives, primarily additional products or services or other gifts, but also recognition as a valued customer. The epitome of this kind of loyalty programme are the airline frequent flyer programmes, first introduced in the early 1980s, which offer free trips and upgrades on the airline. Since then, many other marketers, ranging from the travel industry to financial services to the grocery business, have followed suit. Judging by their popularity, the general consensus of the marketing community seems to be that these kinds of programmes are an effective tool for building customer loyalty and sales.

The premise underlying these efforts is that consumer buying behaviour can be modified in a manner advantageous to the marketer through the rational appeal of 'pay-for-play' - the more the consumer buys, the greater the rewards. The question of whether or not they actually create loyal customers in the sense that most marketers would define loyalty - as an emotional attachment to the brand that drives a high level of brand preference and continued purchase — is often considered secondary, if considered at all. Does it really matter if the programmes merely incentivise repeat buying by consumers who are largely motivated by the rewards and not the 
brand itself, as long as incremental sales are generated at such a low cost that profits are increased?

New and compelling findings about the nature of consumer loyalty and its financial impact on the brand, developed by OgilvyOne Worldwide from a database of more than 600,000 in-depth consumer interviews, argues strongly that it does matter. Incremental, cost-efficient, repeat buying may be synonymous with programme success, but it should not be confused with the attainment of the overarching goal of consumer loyalty and its full range of attendant financial benefits. The findings confirm that such loyalty does indeed spring from an emotional commitment to the brand, but more importantly, they document that the big pay off in sales is only attained when the highest level of emotional attachment is achieved.

It logically follows that to maximise the loyalty benefits of any loyalty programme, success must be evaluated not only in terms of a financially acceptable level of repeat buying, but also by an increasing emotional attachment of programme participants to the brand. Failure to develop this emotional response risks an enormous opportunity cost. Deficient programmes are likely to fall far short of their potential to increase customer retention and share of wallet as well as to be highly vulnerable to competitive attack.

Intriguingly, the findings also reveal that developing a high level of emotional loyalty is an absolutely essential driver of brand leadership, but that attaining the necessary level is no easy matter with conventional marketing communications. In the absence of sizeable and continuous mass media investment, a loyalty programme that develops high levels of attachment may well represent one of the brand's best options for moving up in the brand hierarchy, as Tesco did in the UK.
Such a success story appears, however, to be the exception rather than the rule. Although the evidence as to whether the typical loyalty programme actually does build emotional attachment is not as definitive as the need for that attachment, the available data indicate that the performance of many, if not most, could be substantially improved. Thus, loyalty marketers would be wise to re-examine critically their programmes in light of these findings to ensure that emotional loyalty objectives as well as financial criteria are being met.

\section{WHY EMOTIONAL LOYALTY MATTERS}

Most marketers would agree that if consumers like a particular brand, they will buy more of that brand. Put another way, emotional loyalty is a key driver of behavioural loyalty. But as emotional loyalty increases, does behavioural loyalty increase correspondingly? Until now, there has been scant evidence concerning the precise relationship between how a consumer feels about a brand and how much they buy.

The analysis of more than 600,000 consumers confirms the impact of emotional loyalty to a particular brand on sales of that brand. As might be expected, the findings show that the greater the emotional loyalty to a brand, the more a consumer buys. But more importantly, they reveal that the correlation is exponential, not linear. In the early stages of emotional loyalty development, sales growth is usually regular but relatively modest. But at the highest level of emotional loyalty to a brand, consumers will buy at least twice as much as consumers just slightly less attached to the brand, and often three to four times more. Moving a consumer to the top level usually produces an increase in sales 


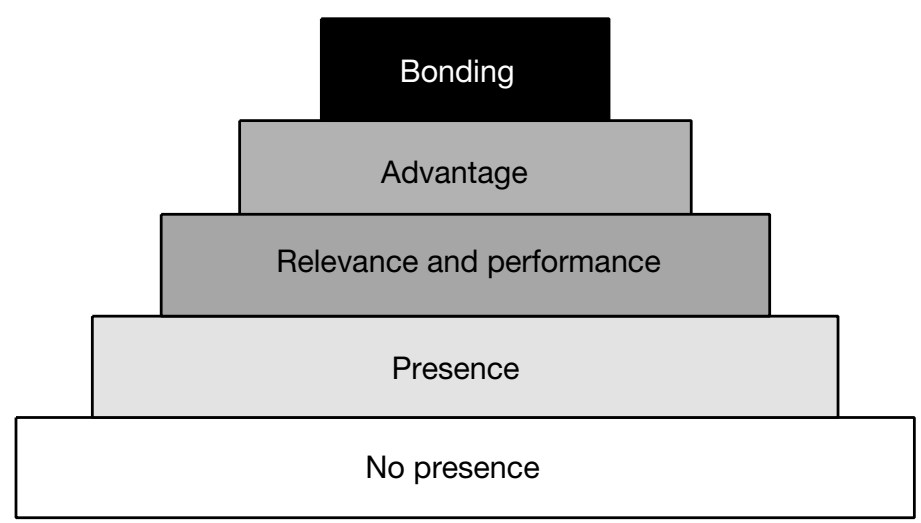

Figure 1 The brand emotional loyalty pyramid

considerably greater than the sum of all previous increases.

As might be expected in light of these impressive increases in sales value, brands that are successful in moving a disproportionate number of consumers up to the highest level of emotional loyalty also enjoy a disproportionate level of success in the marketplace. In category after category, the brand that emotionally bonds the greatest number of consumers, particularly heavy category buyers or users, is the brand leader. Moreover, the additional sales resulting from superior levels of emotional attachment often account for the majority of the difference in market share between two competitive brands.

These important findings are based on a new analysis of more than 600,000 interviews from 31 countries around the world that make up Brandz ${ }^{\mathrm{TM}}$, the ongoing research study first fielded in 1998 by WPP and updated annually. The study, designed and conducted by Millward-Brown, a leading consumer research supplier and, like Ogilvy, a WPP company, covers more than 100 product and service categories and more than 20,000 local and global brands. ${ }^{1}$

To measure emotional loyalty for each brand in each category/country combination, the study probes the feelings of about 400 category buyers or users. Based on their answers, consumers are assigned to one of five levels on an emotional loyalty scale for each brand the brand's emotional loyalty pyramid, illustrated in Figure 1.

At the 'No Presence' level, the consumer has essentially no awareness or understanding of the brand, so there can be no emotional loyalty. At 'Presence' a consumer is aware and has some understanding, but emotional loyalty is minimal. At the 'Relevance and performance' level emotional loyalty begins to build. The consumer feels that the brand is suitable for their needs and budgets, and that it performs acceptably. To reach the 'Advantage' level, consumers must feel that a brand has some quality or attribute that gives them a reason to buy it over others. Thus, a reasonable level of emotional loyalty exists. And finally, there is the 'Bonding' level where emotional loyalty peaks. Consumers who reach bonding believe that the brand's benefits and properties are unique or shared by few other brands. They do not just like the brand, they love it.

For a study of this global scope, it is obviously impossible to measure sales at each level based on actual transactions or observed behaviour, such as that obtainable from a consumer panel. Therefore, as with emotional loyalty, a 


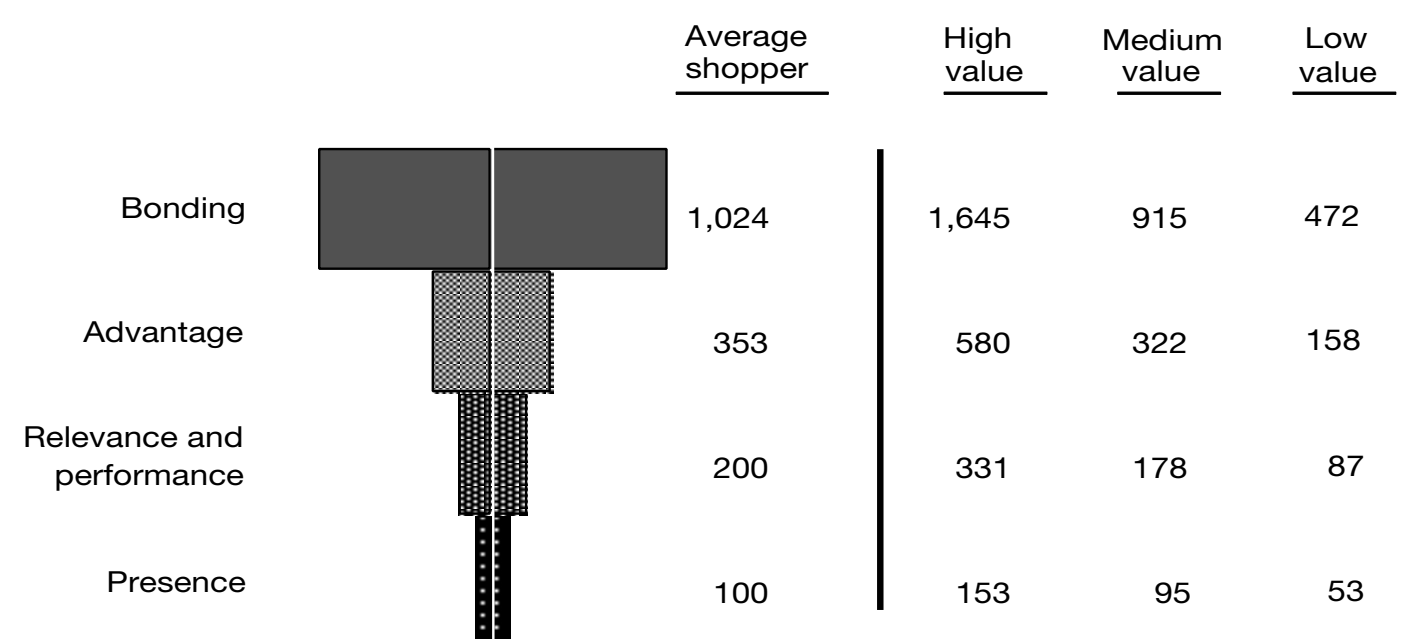

Figure 2 Brand sales at each level of emotional loyalty

consumer's brand and category purchase behaviour must be established by answers to questions in the research interview. For each consumer, category consumption is established based on self-reported current buying habits. Brand sales are then calculated based on the brand's share of self-described future purchase intent.

Importantly, the category and brand consumption questions are totally distinct from and independent of the emotional loyalty questions. Thus, any observed correlation between the two is the result of interdependence between the two measures, not an artifact of the methodology of the interview. Moreover, Millward-Brown has extensively validated the accuracy of the future purchase measure by comparing it to actual subsequent brand-buying behaviour. Therefore, in spite of the methodological limitations of any survey data, a high degree of confidence in the findings is warranted.

This confidence is further heightened by the consistency of the findings. While individual variations in the observed patterns can and do exist, the findings are remarkably uniform across countries and across categories and sectors including packaged goods or fast moving consumer goods (fmcg), durables, services, retail and even business-to-business. In fact, so compelling are the results, Ogilvy has put a database of the entire analysis, christened the Ogilvy Loyalty Index, on its intranet, with the expectation that employees and clients around the world will take it into account as they craft marketing campaigns and brand-building efforts.

\section{THE IMPACT OF EMOTIONAL LOYALTY IN THE GROCERY CATEGORY}

The grocery category in the UK is a typical example of the exponential increase in brand purchases as a consumer moves from advantage to bonding and the resulting impact on brand leadership.

Figure 2 illustrates the amount spent in the average store by UK grocery shoppers at each level of emotional loyalty. (For simplicity and comparability across categories, the sales figures have been indexed to the sales of the average 


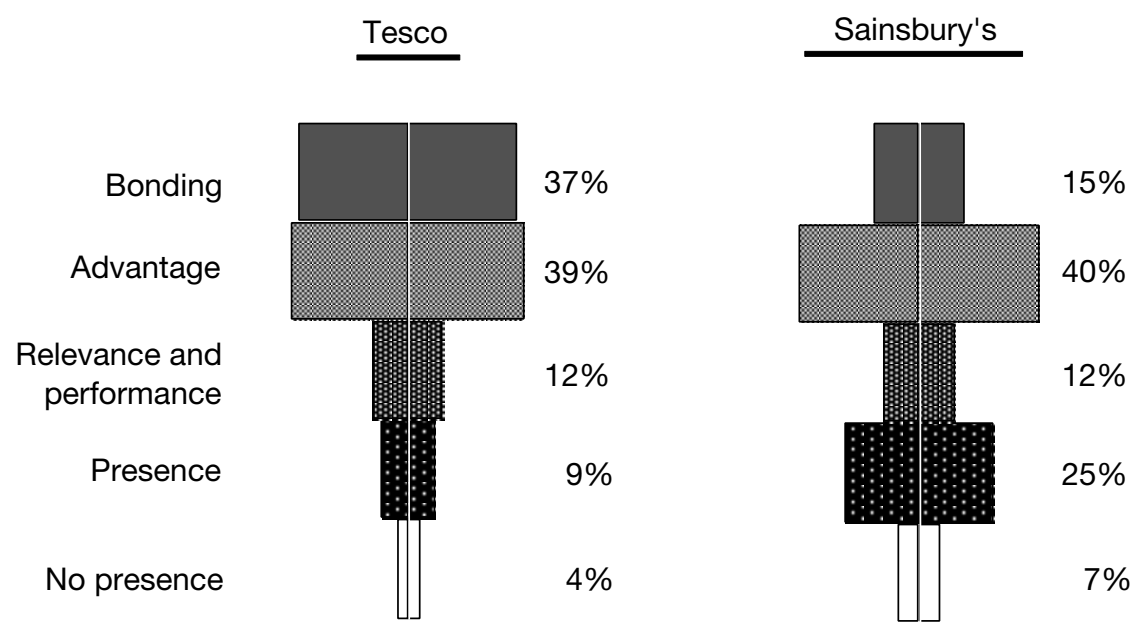

Figure 3 Discrete percentage of category buyers at each level of emotional loyalty

grocery shopper at the presence level, where emotional loyalty is lowest, using 100 as the base.)

As shown in the first column of Figure 2, for every pound spent in a particular grocery store by the average shopper whose emotional loyalty to that store was at the level presence, a shopper at the relevance and performance level spends $\mathcal{L}^{2}$. Similarly, a shopper at advantage spends $\{3.50$, while a shopper at bonding spends more than $\mathcal{E} 10$. The increase in spending between advantage and bonding, close to $f 7$, is almost three times greater than the increase between presence and advantage, only $£^{2.50}$.

The impact of bonding on sales becomes even more pronounced when category buyers are segmented according to the well-known Pareto Principle or '20/80 rule'. Depending on the category, a bonded consumer generally buys four to ten times more than a consumer at presence. But heavy or high-value category buyers, defined as the top third of all buyers in terms of category consumption, generally buy at least 50 per cent more than the average buyer in the category. Thus, in many cases the sales value of a bonded heavy category buyer or user is 15 times more than the average consumer at the base level of emotionally loyalty. As can be seen in Figure 2, this is the case in the UK grocery category where a bonded heavy category buyer purchases more than 16 times as much at a particular store as the average consumer at presence, and well more than half as much again as a bonded medium category buyer.

Two leading brands in the UK grocery category clearly illustrate the resulting impact of high levels of bonding on brand leadership. Based on the reported purchase data in the study, the analysis calculated that Tesco was the market leader with about a 26 per cent share while Sainsbury's trailed at about 16 per cent. As shown in Figure 3, both brands have a comparably high level of awareness, reflected in 'no presence' levels of 4 per cent and 7 per cent respectively. And both brands have moved a substantial percentage of consumers up to the advantage level, where, by definition, consumers perceive the brand to be better on one or more attributes.

But Tesco is clearly superior in achieving the highest level of emotional 
loyalty, bonding, where it enjoys a 37 per cent to 15 per cent advantage over its rival, and an even greater advantage over the other brands in the category. A deeper mining of the data reveals that the additional sales that Tesco gets from its bonded buyers versus the sales that Sainsbury's receives from its own bonded buyers account for 96 per cent of the difference in market share between the two brands. In effect, every additional point of bonding that Tesco has achieved over its competitor accounts for about a half point in market share. In contrast, the difference in sales between the two brands at all other levels counts for very little, irrespective of which brand has the edge.

\section{THE NEED FOR LOYALTY PROGRAMMES TO DEVELOP BONDING}

Despite this impressive impact of bonding on sales and brand leadership, it is still reasonable to ask if it really matters if participants in a loyalty programme become emotionally attached to the brand, as long as they continue to buy at a profitable level. The answer to that question would seem to rest on whether adequate performance is indeed deemed adequate, or if striving for sustainable superior performance is the desired goal.

The first key to superior loyalty programme performance is maximisation of the brand's business with each individual customer, most commonly by gaining most, or all, of the customer's share of category requirements or wallet. But this common loyalty programme objective runs head-on into consumers' proclivity for variety and change. Consumers are repertoire buyers by nature. If they are loyal, they are likely to be loyal to more than one brand. Given a chance to voice their preferred buying style in each category covered by Brandz ${ }^{\mathrm{TM}}$, on average less than 10 per cent of UK consumers agree that there is only one brand they would ever consider in the category. The other 90 per cent would choose between several brands, based either on price or other qualities. These numbers are typical for economically advanced countries.

This repertoire style extends to loyalty programmes as well. Multiple programme membership is often the norm rather than the exception. For example, in the USA, 60 per cent of frequent flyer members belong to more than one programme. More than a third belong to three or more. Among the top 20 per cent of members who account for 70 per cent of the trips, well over half belong to three or more programmes. ${ }^{2}$

Participation in multiple programmes strongly suggests that consumers are seeking to earn rewards in more than one programme. This can easily lead to indifference on the part of the customer as to which brand is chosen on any given purchase occasion, because rewards in all programmes are valuable. Or, it can lead to active manipulation of brand choice, balancing purchases in one programme versus another to increase the totality of rewards. Who among us does not know someone who is juggling their business travel to maximise their rewards from several different airlines? In either of the above cases, each brand with a loyalty programme gets a smaller share of the pie than it otherwise might if it had the sole or preferred programme.

Given these high levels of brand and programme promiscuity, as well as the typical structural constraints inherent in any purchase occasion (eg inconvenience, unavailability, etc), gaining the lion's share of category requirements can be a daunting problem. Nor are there many acceptable solutions. Increasing rewards across the board can be highly 
detrimental to the programme's return on investment (ROI). Increasing rewards selectively to those consumers with the greatest upside share of wallet potential is often impossible because of the difficulty of identifying those high-value prospects based only on their buying rate for the brand, without the corresponding information for the category. For example, a low-value grocery shopper at bonding in the UK buys almost the same amount as a high-value consumer at advantage (index of 472 versus 580 in Figure 2). The former, however, has little or no upside sales potential, while the latter's sales can potentially be tripled if moved up to bonding.

By coaxing the consumer out of the repertoire frame of mind, a high degree of emotional loyalty can help ensure that a loyalty programme participant's share of wallet is as large as practically possible. In fact, gains in purchase intent between advantage and bonding are principally derived from increases in the brand's share of wallet. In the grocery category in the UK, for example, 75 per cent of consumers who reach bonding bond to a single brand, with the rest bonding to two. But they reach advantage for 3.9 brands. Thus, the threefold gain in purchase intent between the two levels (from an index of 353 to 1,024 in Figure 2) is brought about by consumers at bonding allocating most of their brand choice to their preferred brand rather than spreading it out among four.

The second key to superior loyalty programme performance is reduced attrition, which also serves to increase the likelihood that the superior performance is sustained. But given the competitive nature of marketing, it is a rare category where only one loyalty programme exists. And frequently, later entrants devise more lucrative reward schemes to entice customers already enrolled in other programmes. If a participant is attracted by a competitor's rewards, they will no longer continue to buy the marketer's brand, or they certainly will buy less. Marketers have few good weapons to combat competitive attacks. Structural penalties (eg forfeiture of accrued points) can be minimised by intelligent consumer planning. Escalation of the marketer's own reward structure can be costly. In these circumstances, emotional loyalty can provide a powerful exit barrier for programme participants.

The analysis reveals that customer retention in the brand franchise is directly proportional to the level of emotional loyalty. In the grocery category, for example, retention is measured by asking consumers which stores they have ever shopped at and where they currently shop. For customers at bonding for a particular store, only 7 per cent who formerly shopped at the store no longer shopped there, a percentage consistent with structural barriers, such as an inconvenient location. This attrition rate, however, rises dramatically for consumers at lower levels of the pyramid - to 44 per cent for consumers at advantage, 65 per cent for consumers at relevance and performance, and 80 per cent for consumers at presence. If consumers are loyal to the brand and remain loyal, as customers at bonding do, it is logical to assume that they are much more apt to ignore the blandishments of competitors and remain loyal to the programme.

Over and above the opportunity for sustainable superior performance is the opportunity for the programme to contribute to the overall success of the brand. As described above, the exponential growth in brand sales at the highest level of emotional loyalty ensures that bonding a substantial number of consumers goes hand-in-hand with brand leadership. But the analysis also 
illuminates the difficulty of realising that goal.

Tesco and Sainsbury's are both exceptional in terms of their ability to bond a high level of category buyers 37 per cent and 15 per cent respectively. While a relative handful of brands do manage to attain this level, the vast majority of the more than 20,000 brands covered in the study bond less than 10 per cent of their potential customers. The average brand bonds only 5 per cent.

The Brandz ${ }^{\mathrm{TM}}$ study was not designed to answer the question of how emotional loyalty is produced, but nonetheless, it seems reasonable to conclude that advertising and other forms of marketing communications play a major role. There is extensive evidence external to the study that marketing communications do indeed influence consumers' attitudes and feelings about brands. Moreover, the levels of emotional loyalty were measured across all category buyers, not just current brand buyers, tempering the effect of personal experience.

Thus, to the extent that conventional marketing communications are responsible for building emotional loyalty, they are also responsible for the excessively narrow top of the emotional loyalty pyramid observed in the analysis. The substantial percentages of bonding achieved by a select group of brands prove that a significant level of emotional loyalty is attainable. But the brands that have fared best are by and large those that arguably have done so by dint of brute force - consistently aggressive media spending coupled with an appealing message over an extended period of time. These are brands like Coca-Cola, McDonald's and Nike. For brands without the resources or the patience to follow this path, an effective loyalty programme that builds emotional attachment may represent the best opportunity to move up the leadership ladder.

Furthermore, loyalty programmes have a second advantage for building emotional loyalty in that they can be targeted more selectively than mass media. This selectivity limits the budgetary impact and increases the potential return by focusing on the relatively small group of high-value category customers who when bonded are normally worth ten to 15 times as much as customers at the first level. In the absence of deep pockets, this targeting advantage opens the door for virtually any aspiring brand to move up the brand hierarchy by means of an effective loyalty programme - one that builds emotional as well as behavioural loyalty. That this can be a realistic goal rather than a pipedream is illustrated by the Tesco example, discussed in the following section.

\section{DO LOYALTY PROGRAMMES HELP BUILD EMOTIONAL LOYALTY?}

By their nature, loyalty programmes based on rewards tend to incentivise rational behaviour modification. But can this rational appeal and the resulting behaviour change, by itself, lead to emotional change? Or do marketers have to do more within the context of their programmes to create the desired levels of emotional attachment? Moreover, is there evidence that even with this objective in mind, loyalty programmes are capable of generating a high level of emotional response?

While the Brand $z^{\mathrm{TM}}$ data do not address the impact of loyalty programmes directly, they clearly demonstrate that repeat purchasing per se has little or no impact on emotional loyalty. In many categories around the world, particularly fmcg, retailers' own-label brands (also 
referred to as 'private label') have carved out a sizeable market share based on their low price. (In this regard, the UK is a bit of an exception in that retailers' own-label brands are often considered to be of equal quality and can even be premium priced.) But the bonding level for retailer brands in most countries hovers around zero, despite substantial levels of purchase intent. Repeat buying has not endeared them to their users.

Repeat buying in the context of a typical loyalty programme does, however, appear to produce some modestly greater measure of emotional response, although performance is erratic and substantial improvement is possible. OgilvyOne offices around the world were asked to identify those brands in each country that had developed major programmes with significant spending and substantial enrolment. Their bonding scores were then compared with similar-sized brands in the same categories. Brands with active programmes had, on average, twice the level of bonding of brands without programmes. But on a case-by-case basis, brands with programmes had higher bonding levels than their competitors only about two out of every three times, or only somewhat better than the 50 per cent that would be expected by chance.

These somewhat contradictory results can best be explained by the broad cross section of loyalty programmes that were identified in the survey - everything from pure points programmes to preferred customer or 'club' programmes, with no rewards other than special recognition and individual communication. Although the analysis is still going on, the initial conclusion is that any loyalty programme, by virtue of its reaching out to customers individually, makes them feel 'special' and thus produces some modest emotional response. (This relatively weak loyalty programme effect was first noted in an earlier survey conducted by the Henley Centre in the UK, which reported that only about 12 per cent of participants in loyalty programmes agreed that the programme had 'made them think more highly of the company'. ${ }^{3}$ ) But, generally speaking, only programmes which go beyond simple financial rewards and develop personal relevance and emotional response, win big in terms of bonding. Those that do not develop personal relevance and an emotional response enjoy a smaller bonding advantage, if any. Thus, what marketers do, or do not do, to build emotional attachment into their programmes is critical to whether that attachment is actually produced.

Tesco in the UK is an example of a brand whose programme has won big by attempting and succeeding in building a high level of emotional attachment. In fact, the win was so big that it helped propel the chain to market leadership.

In the mid-1990s, Tesco became the first supermarket in the UK to implement an aggressive loyalty programme aimed at frequent buyers. Although causality is always difficult to prove, the apparent effect on market share was dramatic. Tesco soon passed Sainsbury's to become the brand leader. Based on the data already cited, Tesco's success at changing consumer behaviour went hand-in-hand with increasing consumers' attachment to the brand and bonding a greater number of category shoppers than its rival, particularly high-value shoppers (whose bonding level to the brand is 41 per cent versus 37 per cent overall).

After observing Tesco's success, Sainsbury's belatedly countered with a programme of its own. But arguably, the Sainsbury's programme's relative lack of impact versus Tesco's can be ascribed to more than just a slow start. In contrast to the Sainsbury's 'one size 
fits all' basic points programme approach, Tesco has built its programme around a complex and powerful segmentation of the Clubcard database, based on a variety of factors including demographics, lifestyle, eating habits, brand allegiance and price sensitivity. Through this deeper understanding of the franchise, they have delivered different messages and offers to different segments, a strategy that provides greater recognition and service to participants and one that seems bound to ensure greater personal relevance and thus a greater emotional response.

Tesco is not the only proof that a well-crafted loyalty programme can create exceptional levels of emotional response. The spirits category in the USA offers one of the more startling examples, even more so because it demonstrates that high levels of bonding can be developed by spending wisely with a loyalty programme rather than by simply spending more.

Dating back to the 1980s, Absolut vodka has been the leading brand in terms of measured media, with about US $\$ 30 \mathrm{~m}$ annually placed behind a critically acclaimed advertising campaign. ${ }^{4}$ Although Absolut's level of bonding is high in comparison with category and global norms, it is not consistently higher than two competitors in the category Jack Daniels and Crown Royal. These are brands that it has historically outspent by roughly 50 to 100 per cent. Their secret would seem to be the long-standing loyalty programmes both brands have sponsored, loyalty programmes that offer no ongoing 'pay-for-play' benefits whatsoever, but that depend entirely on their cleverness and creativity to provide the personal recognition and relevance that drive extraordinary levels of attachment to the brands.

\section{SUMMARY AND INDICATED ACTIONS}

As marketers have long suspected, emotional loyalty does drive behavioural loyalty. But the correlation is not linear. The greatest gains in purchasing and retention are only achieved when a consumer's attachment to the brand reaches the highest level. So powerful is the effect on sales, the leader in market share is usually the brand with the greatest number of emotionally loyal customers.

Therefore, in order to maximise effectiveness, the objective of loyalty programmes must be to develop high levels of emotional loyalty among programme participants, not just repeat buying. High levels of emotional loyalty increase customer retention by helping insulate the programme against competitive offerings. They also produce higher levels of share of requirements by counteracting consumers' tendency to distribute their purchases across several brands and programmes. Moreover, because of the difficulty of building high levels of emotional loyalty through conventional marketing communications, a programme that achieves this objective may be the most cost-effective method of helping a brand move up the hierarchy of brand leadership.

While specific prescriptions for how loyalty programmes can best drive emotional loyalty are beyond the scope of this paper, the general principles of offering interesting and involving communications and experiences, above and beyond rewards earned, are sure to apply. The considerations or benefits that drive emotional loyalty will vary brand-by-brand, category-by-category and country-by-country. Once determined, the way these drivers are subsequently articulated and communicated will be equally varied. Approaches that have proved effective 
have included newsletters, personalised letters, offers, websites, announcements of product news, recognition as a valuable customer and tangible demonstrations of brand superiority. Many other approaches are certain to exist. The key is matching the approach to the proper drivers and, ultimately, both to the brand.

Similarly, the effectiveness of the programme in building emotional loyalty must be a measurement priority. Absolute precision and replication of the emotional loyalty pyramid classification is less important than a reliable gauge of whether consumer attachment to the brand is being positively affected by the programme relative to non-programme participants. By building this measure into the evaluation process, marketers can better assess the long-term impact of the programme as well as the likelihood of sustaining or even improving repeat buying patterns.

\section{References}

1 For more information about Brandz, go to www.wpp.com and search 'Brandz'.

2 Mediamark (MRI), USA, 2002 Doublebase.

3 The Brann/Henley Centre (1994) Loyalty Survey.

4 For more information about the Absolut campaign, go to www.absolutad.org or see Lewis, R. W. (1996) 'Absolut book: The Absolut vodka advertising story', Charles E. Tuttle Co., Boston. 